Daimon. Revista Internacional de Filosofía, Suplemento 5 (2016), 109-118

ISSN: 1130-0507 (papel) y 1989-4651 (electrónico)

http://dx.doi.org/10.6018/daimon/268471

\title{
El cuerpo sexuado en los diálogos de Platón
}

\author{
The Sexed Body in Plato's Dialogues
}

\author{
VÍCTOR HUGO MÉNDEZ AGUIRRE*
}

\begin{abstract}
Resumen: Se postula que la categoría «género», entendida en términos de construcción social impuesta sobre el cuerpo sexuado, fue propuesta originariamente por Platón. En primer lugar, se ha señalado que el «cuerpo homérico» fue pensado como conjunción de miembros y órganos. En segundo lugar, los antiguos griegos creían que el útero era la causa de varios desórdenes psicosomáticos y una razón por la cual las mujeres deberían estar subordinadas a los hombres. Por último, Platón descubrió que los testículos causan «histeria masculina». Así, hombres y mujeres son igualmente susceptibles al vicio y la enfermedad. Sucintamente, la antropología platónica es completamente igualitaria.

Palabras clave: Platón, cuerpo, alma, género, sexo.
\end{abstract}

\begin{abstract}
This paper argues that the category of «gender»-understood as the social construction imposed upon sexed body- was first proposed by Plato. To start with, it has been pointed out that the «Homeric body» was thought as the conjunction of limbs and organs. Secondly, the ancient Greeks believed the uterus was the cause of several psychosomatic disorders and one reason why women should be subordinated to men. Finally, Plato found that the testicles are the source of «masculine hysteria». Thus, men and women are equally prone to vice and disease. To put the problem succinctly, Plato's anthropology is completely egalitarian.
\end{abstract}

Keywords: Plato, body, soul, gender, sex.

\section{El cuerpo en los orígenes y los orígenes del cuerpo: una sinécdoque particularizante}

El autor de Simbolo e corpo no se equivoca al incluir el cuerpo entre las dimensiones de lo humano. Dicho escritor hace hincapié en que la «corporeidad» constituye parte de «la dimensión propia del hombre» (Santasilia, 2016, 96). Sin embargo, cuando menos en Occidente, aunque parezca contrario a la intuición, esta categoría se consolida progresivamente paralelamente al concepto de alma.

Fecha de recepción: 03/05/2016. Fecha de aceptación: 20/07/2016.

* Universidad Nacional Autónoma de México. Investigador Titular adscrito al Instituto de Investigaciones Filológicas. Correo electrónico: victormendez1971@gmail.com Líneas de investigación: Platón, éticas clásicas y estudios de género. Publicaciones recientes: MÉNDEZ AGUIRRE, Víctor Hugo (2014): «Ética tau y utopía en Aristóteles», Theoría. Revista del Colegio de Filosofía (México), n 27, pp. 43-53; y MÉNDEZ AGUIRRE, Víctor Hugo (2016): «Nombre e identidad de la mujer griega. Gyné y dámar de Homero a Platón», in: Francesca M. Dovetto y Rodrigo Frías Urrea (eds.): Nome e identità femminile nel mondo antico, Roma, Aracne editrice, pp. 317-334. 
Sôma es la palabra griega que suele ser traducida por cuerpo. Pero resulta menester tener en cuenta que en los orígenes de la literatura clásica todavía no había adquirido plenamente dicha acepción. En Homero sôma alude al cuerpo exclusivamente cuando éste ya ha perdido la vida, es el cadáver antes que el cuerpo propiamente dicho (Chantraine, 1968, 1083).

Bruno Snell se hizo célebre por su tesis de acuerdo con la cual el hombre homérico carecía de nuestro concepto unitario de cuerpo. «A nosotros se nos hace difícil creer que en un tiempo el hombre no haya tenido una concepción clara, ni correspondiente expresión, del cuerpo como tal. De las expresiones mencionadas, que pueden tener en la frase el lugar de lo que luego fue sôma, sólo los plurales gyîa y mélea [miembros], etc., denotan el cuerpo en su corporeidad» (Snell, 1965, 22).

Homero recurre a diferentes palabras para referirse al cuerpo vivo. Algunas de ellas remiten a su límite espacial, ya sea a su estatura o a la piel que lo envuelve. «Démas» refiere a «figura, cuerpo; estatura» (Tapia, 2013, 151). En la Odisea X, 239-240 se relata que cuando Circe transforma en puercos a los marineros «ellos tenían las cabezas, la voz y las cerdas de puercos, y el cuerpo (démas), mas su mente estaba firme, justo como antes» (Homero, 2013, 165). Emilio Crespo hace suya la idea de Snell al encontrar en la «piel» el tropo con el que alude Homero al cuerpo. «El término homérico que más se aproxima por su significado al cuerpo es khrós, que se traduce como 'piel' o 'carne' y que en los poemas homéricos designa propiamente la superficie o el límite externo del ser humano que sirve como sustrato del color y de la textura» (Crespo, 2015, 49).

En la línea 26 de la Teogonía de Hesíodo las Musas se refieren a los humanos llamándolos «vientres tan sólo» (Hesíodo, 1986, 1). Los mortales, cuya existencia depende de la ingesta de alimentos, procedentes de la tierra, no son otra cosa que vientres.

La totalidad del cuerpo del individuo es representada mediante un tropo a través de la alusión a uno de sus órganos. «Es la sinécdoque particularizante en la que por medio de lo particular se expresa lo general; por medio de la parte, el todo; por medio de lo menos, lo más; por medio de la especie, el género; por medio del singular, el plural» (Beristáin, 2001, 474). El uso de tal figura retórica para referirse al cuerpo y, se diría ahora, a la persona, no es privativo de la literatura homérico-hesiódica ni refleja necesariamente una fase primitiva y superada de la mentalidad humana. De hecho, el «rostro» ha sido asociado a la totalidad de la persona en diferentes épocas y latitudes. Los tlamatinime, sabios o filósofos aztecas precolombinos, empleaban el difrasismo «rostro y corazón» para referirse a la totalidad de la persona. «Rostro es, pues, para los tlamatinime la manifestación de un yo que se ha ido adquiriendo y desarrollando por la educación» (León-Portilla, 2006, 190). En cierta filosofía de los últimos siglos, particularmente en la línea de Lévinas, la «corporalidad» encuentra «su representación a través [de la] noción de rostro» (Azaovagh, 2011, 73).

Sea como fuere, aunque Homero y Hesíodo pueden ser considerados los educadores indiscutibles de Grecia, según el testimonio de Heródoto, lo cierto es que en sus obras todavía no se consolida plenamente el concepto «cuerpo». ¿Cuándo ocurre tal hazaña intelectual? La autorizada opinión de filólogos como Snell y Crespo percibe que esto se registra en tiempos posthoméricos. Y tal proceso es solidario de la emergencia del concepto de alma, en particular del alma que es inmortal núcleo de identidad del individuo. 


\section{Hacia el tándem cuerpo/alma}

En la Nekyia homérica, el canto 11 de la Odisea, el alma en el Hades es algo prácticamente inane. Esta concepción parece haber impregnado el imaginario social heleno incluso a finales de la época arcaica. En una bien conocida ánfora ateniense de cuello de figuras negras del Pintor de Diosfos ( ca. 500-490 a. C.), perteneciente a la colección del Museo de Louvre, Hipno y Tánato levantan el cadáver de Sarpedón. El alma del muerto es representada por una pequeña imagen que se aleja del cadáver, haciendo hincapié en la asimetría entre aquélla y éste.

El griego homérico carecía tanto de un concepto unitario de cuerpo como de alma. «Esta carencia de un concepto unitario de cuerpo lleva indefectiblemente a la inexistencia del concepto opuesto, el de alma [...] para el griego homérico, no existe todavía una neta distinción entre ambos conceptos, sin duda porque [...] todavía no se han conformado de forma unitaria» (Martos, 1999, 56).

Cuando menos dos líneas de antropología filosófica parecen haber competido en lo atinente a la emergente concepción del complejo alma/cuerpo. Por una parte, cierto monismo postula que sin una no puede subsistir la otra. Esta concepción va desde el alma aire de Anaxímenes hasta las almas atómica epicúreas, sin olvidar el alma percepción protagórica. Por otra parte, el dualismo psicosomático, tanto en sus versiones órficas como pitagóricas, también contribuyó de manera decisoria a la conformación de los conceptos de alma y cuerpo como entidades unitarias. Ambas concepciones antropológicas, la unitaria y la dualista, parecen haber coexistido en las mentalidades de los griegos de época arcaica y clásica. El dualismo psicosomático, particularmente en sus líneas órfica y pitagórica, parece haber contribuido a la consolidación de concepciones unitarias tanto de cuerpo como de alma.

Oscilando entre religión y filosofía, pitagóricos y órficos postularon la inmortalidad del alma y su independencia con respecto al cuerpo. Aunque existe cierto debate al respecto del presunto silencio pitagórico, los órficos sí nos heredaron diversos textos. Algunos de ellos son bien conocidos desde hace siglos, otros, como el Papiro de Derveni, han sido descubiertos recientemente, apenas en 1962. «La oposición cuerpo/alma con menosprecio del cuerpo frente al alma la hallamos claramente atribuida a los órficos en las laminillas de Olbia [...] En una de ellas leemos [...] Dioniso (en nom. o dat.) / mentira verdad / cuerpo alma» (Bernabé, 1995, 219).

En Píndaro, poeta que habla de la inmortalidad del alma, la «suma de sus miembros» ya ha cedido su lugar a lo que ahora se entiende por cuerpo. En las Estrofa y Antistrofa 4 de la Nemea VII (70-73), se dice: «De familia Euxenida, Sógenes: yo lo juro: no, traspasando el término, he de lanzar mi rápida lengua, tal como el asta por el bronce atajada, esa que despidió de las peleas el cuello y el poder no sudados, antes de que al sol quemante el cuerpo (gŷ̂on) se extendiera» (Píndaro, 2002, 29). Snell comenta al respecto de este pasaje que en él «Píndaro tenía ya el concepto de cuerpo, se halla también en Nem. 7,73, donde gyîon se usa en singular; también aquí se trata de un sustituto poético de sôma» (Snell, 1965, 23).

A pesar de que se puede constatar la unidad paralela de cuerpo y alma entre algunos contemporáneos y seguidores de Píndaro, lo cierto es que las tesis de origen homérico del cuerpo como «suma de sus miembros» y de las almas corporales no son abandonadas completamente, ni siquiera ante la emergencia de la ciencia que hace del cuerpo su objeto de estudio: la medicina. 
Esta evolución explica una de las peculiaridades más desconcertantes de algunas antropologías filosóficas griegas, como la de los diálogos de Platón. Por una parte, los conceptos cuerpo y alma se encuentran consolidados como núcleos de unidad e identidad humana en época clásica. Por la otra, «almas corporales», esto es, órganos que desempeñan funciones psíquicas y que incluso parecen ser el elemento hegemónico del ser humano en algunos autores, no desaparecen del todo del imaginario social de la época.

Los órganos de los sistemas reproductivos de hombres y mujeres difieren entre sí. Los úteros de éstas van a acaparar la atención de los tratados ginecológicos hipocráticos nimbando de una pretendida cientificidad los prejuicios patriarcales de los griegos.

\section{El cuerpo sexuado y sus enfermedades en los tratados hipocráticos}

La primera época de la ilustración, el siglo V a. C., atestiguó el apogeo de los hipocráticos. Sus teorías médicas ilustradas, oscilando entre relatos míticos antiquísimos, concepciones populares de sus contemporáneos y el espíritu científico que configurará el rostro de Occidente, constituyen un elemento esencial de las antropologías filosóficas de época clásica. «El cuerpo humano es así visto como un recipiente complejo y un tanto misterioso, cubierto por la piel y articulado por el esqueleto, que puede ser afectado por heridas externas y desequilibrios internos» (García, 1999, 67).

Un tema recurrente en sus tratados ginecológicos es el de un órgano que, evocando tanto a Homero y Hesíodo, parece reclamar cierta primacía con respecto al resto del cuerpo y se solivianta en caso de no recibir la atención requerida: la matriz (hystére). Una vez alcanzada la menarca la matriz permanece en un equilibrio precario dentro del cuerpo. En caso de no registrarse una situación idónea, incluida la humedad, ésta se desplaza e invade espacios pertenecientes a otros órganos, generando diferentes disturbios psicosomáticos. Se trata de la enfermedad llamada histeria.

El Sobre la naturaleza de la mujer ofrece un itinerario de los diferentes destinos preferidos por las matrices vagabundas. Éstas pueden dirigirse al corazón, a la cabeza, a los hipocondrios, a los pies y las piernas, a la cadera, a los costados, afuera de los genitales, al ano, a la izquierda, la derecha, o a uno y otro lado.

Los desplazamientos de las matrices causan estragos en la salud de las afectadas. En Sobre la naturaleza de la mujer 3 se resalta que «cuando la matriz se dirige hacia el hígado, hay pérdida repentina de voz, castañeteo de dientes y el color de la piel de la enferma se vuelve lívido. Estos trastornos sobrevienen de repente, pese a estar sana la mujer, y les ocurren a las mujeres vírgenes sobre todo de edad avanzada y a las viudas que, pese a ser jóvenes y haber dado a luz, enviudan» (Hipócrates, 1988, 361).

El Sobre las enfermedades de las mujeres I 1 inicia señalando que «en lo referente a las enfermedades de las mujeres, digo que una que no ha dado a luz hijo alguno padece trastornos menstruales más agudos y frecuentes que la que ha tenido hijos» (Hipócrates, 1988, 47).

La comunidad científica de Grecia clásica generó la ginecología hipocrática. No hay duda de que ésta es un capítulo de la historia de la ciencia médica. Sin embargo, ¿se encuentra exenta de ideología? 


\section{Cuerpo sexuado e ideología}

¿Por qué tanta atención al útero y sus enfermedades? Una explicación plausible podría ser que éstas ofrecieron una base científica a la naturalidad de la organización patriarcal de la sociedad. Los tratados ginecológicos hipocráticos en general gravitan en torno a la idea de que el matrimonio es una institución natural dado que sólo él y la subsecuente maternidad pueden garantizar la salud y la vida misma de las mujeres. «L'utero [è] causa unica di tutte le patalogie femminili, è un animale selvaggio e riottoso che solo la terapia fallica, riconducendolo letteralmente al suo sito naturale è veramente in grado di addomesticare» (Lombardi, 1994, 25).

Parafraseando el célebre libro de López Austin, Cuerpo humano e ideología (1980), podría afirmarse la existencia en Grecia de una ideología patriarcal construida en torno del cuerpo sexuado. En el caso de estudio de esta pesquisa, Grecia antigua, «son cuestiones que descansan en una política, y una política masculina que precisa la reflexión médica para una mayor eficacia: una gineconomía, política en relación a la mujer que, en este caso, es una política ejercida por los hombres sobre el cuerpo femenino. La política de dos hombres: el padre y el marido; la política de todos los hombres, por mediación de la ley» (Rousselle, 1989, 48).

No obstante lo anteriormente dicho, no todos los filósofos antropólogos atenienses se adhirieron a tal empresa, algunos, como intentaré mostrar, la cuestionaron, y entre ellos destaca Platón.

\section{Cuerpo y alma en los diálogos de Platón}

Platón construye progresivamente sus propias teorías relativas al cuerpo y el alma haciendo suyas, no sin antes depurarlos de todos aquellos aspectos que él considera impropios, ideas procedentes de la tradición que hereda. Alberto Bernabé ha empleado el concepto «transposición», acuñado originariamente por Diès, para referirse a la manera en que Platón absorbe críticamente ideas procedentes de otras fuentes para formular sus propias y muy personales teorías (Bernabé, 2011, 233). Esta tesis de la transposición resulta más que afortunada en lo atinente a la antropología filosófica de los diálogos. Aunque no rescata completamente a Homero ni en su cuerpo «suma de sus miembros» ni en su alma inane, sí presta mayor atención a Píndaro, los pitagóricos, los órficos y los hipocráticos. Por una parte, hará suya y le imprimirá su impronta a la tesis de la inmortalidad del alma al relacionarla con el mundo de las Ideas antes que con el del devenir. Por otra parte, el cuerpo puede formar parte de lo sensible y resultar susceptible de cambio y corrupción, no obstante, mientras vive, es una unidad, quizá lábil pero unidad al fin.

La preeminencia del alma sobre el cuerpo tiende a minimizar las diferencias entre hombres y mujeres, en particular si se toma en cuenta que al momento de la reencarnación quienes fueron hombres en su otra vida pueden optar libremente por encarnar en cuerpos femeninos. Lo contrario funciona igual, quienes anteriormente fueron mujeres al momento de la transmigración de su alma se encuentran en la posibilidad de animar cuerpos viriles.

No se puede soslayar que las concepciones platónicas acerca del cuerpo y el alma evolucionan con el tiempo. En Alcibíades -si este diálogo es realmente platónico- se plantea 
que el ser humano es su alma y que el cuerpo no es otra cosa que su instrumento. En 130 c, según la canónica numeración de Stephanus que será mencionada cada vez que se cite un diálogo, se afirma: «Y puesto que ni el cuerpo ni el conjunto son un hombre, queda, creo, o que no es nada, o si es realmente algo, se sigue que el hombre no es otra cosa que alma» (Platón, 2013, 199). En el Banquete, donde se celebra el triunfo de Agatón y Eros preside las conversaciones, no se habla explícitamente de la inmortalidad del alma pero se revelan los misterios del amor de acuerdo con los cuales lo mortal puede adquirir la inmortalidad a través de la procreación. En el Fedón Sócrates a punto de ingerir la cicuta define la filosofía como una preparación para la muerte dando pábulo al desprecio de lo corpóreo y el encumbramiento del alma aislada en su pureza. En República y Fedro el alma inmortal es tripartita. En Timeo, con también una tripartición del alma, parece retomarse la tesis de las almas corporales cuando se señala que el alma concupiscible se aloja entre el diafragma y el ombligo, con el hígado como núcleo del cual irradia la mántica, la irascible entre el diafragma y el cuello, gravitando en torno de corazón y pulmones y la racional en la cabeza.

¿Qué dice Platón del cuerpo? Afirma que pertenece al orden del devenir y que por lo tanto está sujeto a la muerte. Pero por mortal y efímero que sea, mientras se mantenga con vida constituye una unidad. El Sócrates que protagoniza Filebo, en el pasaje 29 d, pregunta a Protarco, «¿No llamamos nosotros cuerpo a todas esas cosas de las que acabamos de hablar cuando vemos que componen una unidad?» (Platón, 2011, 99).

Los cuerpos humanos poseen sexo biológico. Hombres y mujeres tienen cabezas e hígados, partes corpóreas esenciales para el conocimiento de acuerdo con la fisiología del Timeo. En esta obra Platón se adhiere a las creencias populares y a los conocimientos hipocráticos imperantes en su sociedad, claramente patriarcal. Sin embargo, la antropología filosófica sobre la que se edifica su utopía por antonomasia, la Calípolis o ciudad bella de la República, sorprende por su objetividad. Las únicas diferencias relevantes entre hombres y mujeres que son percibidas por el autor del diálogo sobre la justicia radican en los respectivos sistemas reproductivos y en la mayor fuerza física de los primeros. Por una parte, según República 454 d-e, «las mujeres paren y los hombres procrean» (Platón, 2000, 164). Por la otra, de acuerdo con República 455 d-e, «la mujer, por consiguiente, participa por naturaleza en todas las funciones, y en todas igualmente el varón, sólo que en todas es más débil la mujer que el varón» (Platón, 2000, 165). En las acertadas palabras de Giovanni Cassertano, «è identica la loro natura» (Cassertano, 2010, 126).

En su conquista del concepto del cuerpo unitario Platón, a pesar de todo, no renuncia completamente a las almas corporales, particularmente en el Timeo. Y estas concepciones tradicionales le sirven para explicar, cuando menos en parte, tanto la salud/enfermedad como la virtud/vicio.

\section{Los males que aquejan a los cuerpos y sus respectivas téchnai}

Téchne suele ser traducido como arte o técnica. Aunque tal traducción no vierta completamente el sentido de la palabra original en la lengua de recepción ya se ha vuelto canónica. Puede decirse que «una téchne implica siempre la posesión de una destreza, habilidad o pericia que permite al que la posee, el technítes o experto, aplicar correctamente determinados conocimientos organizados dirigidos a un fin» (Aguirre, 2013, 94). 
En lo relativo al cuerpo, el objetivo de las artes abocadas a él es su cuidado, esto es, su therapeía. En Gorgias 464 b Sócrates señala que para el cuidado del cuerpo coadyuvan dos artes complementarias: «la que se relaciona con el cuerpo, no te la puedo nombrar así como única, sino de este único cuidado del cuerpo nombro dos partes: por un lado, la gimnasia, por otro, la medicina» (Platón, 2008, 25). Las téchnai abocadas al cuidado del cuerpo son la medicina y la gimnástica, ambas bien valoradas por el autor de los diálogos. «Dizer que o filósofo não dedica sua vida exclusivamente ao cuidado do corpo não significa dizer que ele o odeie, essa não é a intenção de Platão, logo porque é presente em vários âmbitos de sua filosofia que ele, o corpo, tem sua participação, seja na dimensão ética ou epistemológica» (Filgueiras, 2011, 179).

Debilidad y fealdad se encuentran íntimamente asociadas en el imaginario social griego clásico, «la fealdad clásica se define ante todo como la privación de la belleza y de la armonía que se deriva de ella [...] De ahí que todo lo que escape al ideal del cuerpo atlético y por tanto a la norma de excelencia, se acerque a la fealdad» (Moreno, 2015, 195).

El feo/deforme por antonomasia en los orígenes de la literatura es Tersites. Para el aristocrático Homero queda claro que tal personaje es feo y malo en virtud de su falta de nobleza. Pero el ideal de la bondad bella se modifica radicalmente con el nacimiento de la ética.

La fealdad de Sócrates es un tópico tanto en las obras de Platón como en las de Jenofonte. A pesar de las diferencias entre ambas, lo que queda claro es que las virtudes del filósofo ágrafo lo embellecen independientemente de su nariz chata y lo abultado de su vientre. La bondad/belleza del cuerpo para los socráticos requiere tanto ejercicio físico como cuidado del alma, esto con independencia del sexo biológico.

\section{Enfermedades del cuerpo sexuado en los diálogos de Platón}

Siendo la comida, la bebida y el sexo los principales deseos en el imaginario social heleno, no resulta difícil comprender las razones por las cuales Platón eligió el lugar del alma concupiscible. En lo relativo al cuerpo sexuado femenino, hace suya parte no desdeñable de la teoría ginecológica hipocrática señalando la relativa independencia del útero dentro del cuerpo como conjunto. En Timeo $91 \mathrm{c}$-d se puntualiza:

las que son llamadas matrices y úteros, un ser viviente interior deseoso de la procreación de hijos, cuando sucede que está infecundo por mucho tiempo más allá del período oportuno, lo soporta con dificultad y se irrita, y errando por todas partes a través del cuerpo, al no permitirle respirar le arroja a las angustias más extremas y provoca todo tipo de enfermedades, hasta que, ya que el deseo y el amor de ambos los impulsó, ellos, y como quienes acto seguido cosechaban de los árboles un fruto, mientras sembraban como en tierra labrada criaturas invisibles por su pequeñez e informes, y separaban de nuevo los órganos, ellas estuvieron en condiciones de nutrir grandes las criaturas dentro y después de eso pudieron consumar la generación de seres vivos cuando los condujeron a la luz (Platón, 2004, 228-229).

En lo relativo al cuerpo masculino, la carencia de útero no lo inmuniza del riesgo de histeria. Aunque en el varón no existe ninguna hystére que se desplace debido a reseque- 
dad, la producción de esperma puede acarrear consecuencias igualmente indeseables, una especie de histeria masculina, anticipando a Charcot. En Timeo 86 c-e se afirma:

Así, todo el que genera un esperma abundante y fluido alrededor de la médula, y como si fuera un árbol por naturaleza más fructífero que lo adecuado, al proporcionarse en cada ocasión por medio de sus deseos y productos de su entorno muchos sufrimientos y muchos placeres, a pesar de que está desquiciado la mayor parte de su vida por causa de sus grandes placeres y penas, porque su alma está enferma y se halla sin uso de razón por la acción de su cuerpo, no se le considera como un enfermo sino como un hombre voluntariamente malo. Pero la verdad es que la incontinencia respecto de los placeres sexuales se transformó en una enfermedad del alma debido a la constitución fluida y en estado húmedo de una sola substancia, producto de los huesos del cuerpo. Y quizá prácticamente de todo tipo de placeres se dice que son una inmoderación y un motivo de reproche injustamente: porque nadie es malo voluntariamente, sino que, en virtud de una cierta constitución viciosa del cuerpo y un género de vida sin educación el malo llega a ser malo, y esto es odioso para cualquiera y le sobreviene como un mal. Además, en lo concerniente específicamente a los dolores, el alma de un modo semejante adquiere mucha maldad por causa del cuerpo (Platón, 2004, 219-220).

Platón complementa la ginecología hipocrática con una teoría del cuerpo sexuado masculino. Éste, como tal, no le interesa a Platón; lejos está del espíritu científico de los tratados biológicos de su discípulo. Pero en el diálogo donde acusa a los varones injustos y cobardes de reencarnar como mujeres afirma la existencia de una clase de «histeria masculina» cuyas connotaciones morales le preocupan. Los hombres carecen de matriz que se desplace dentro de sus cuerpos por causa de la sequedad; pero es precisamente un exceso de humedad, inverso al que amenaza a las mujeres, lo que los «histeriza».

Chantraine subraya que los griegos solían distinguir la lascivia en función del género del sujeto que la experimenta: «mákhlos, «lascif», dit en principe des femmes, tandis que lágnos se dit des hommes» (Chantraine, 1968, 673). Si el pensamiento patriarcal hizo hincapié en la lascivia presuntamente inherente a las mujeres (makhlosýne), los moralistas clásicos también estuvieron conscientes de los estragos generados por la lascivia masculina (lagneía). Y si en la tragedia ática Fedra se suicida y difama a Hipólito al ser derrotada su razón por sus pasiones, en la tragedia de Atenas la histeria masculina, quinta esencia de la personalidad tiránica, provocó los tan temidos episodios de disensión o stásis que estremecieron a varias póleis clásicas. ¿Qué tragedia es mayor? ¿Treinta Fedras sufriendo hasta el suicidio por los desplazamientos de sus matrices o la ciudad de Atenas masacrada por los deseos descontrolados de sus treinta tiranos?

\section{Consideraciones finales}

Es un lugar común que el Sócrates platónico prácticamente instaura la concepción del alma imperante en la mayor parte de la historia de Occidente. Suele atribuirse al platonismo una preeminencia del alma con respecto al cuerpo. Sin negar lo anterior, la presente 
comunicación ha hecho hincapié en que la antropología de los diálogos platónicos también incorpora una teoría desarrollada del cuerpo. El dualismo psicosomático planteado por Platón, como se ha demostrado, dedica más tiempo al cuerpo de lo que usualmente se piensa.

Apoyándose y cuestionando al mismo tiempo la ciencia médica y los prejuicios patriarcales de la época que le tocó vivir, Platón postula que las diferencias biológicas de los cuerpos sexuados se reducen a la fisiología de la procreación y a las dimensiones de los cuerpos; pero tales características no implica ninguna consecuencia en lo relativo al lugar de las mujeres y de los hombres en la sociedad. Y tal concepción del cuerpo sexuado resulta sorprendentemente vigente si se toma en cuenta la categoría género prácticamente omnipresente en las teorías sociales y las sociedades contemporáneas.

Sucintamente, la antropología filosófica contenida en las utopías platónicas prefigura la categoría contemporánea de género entendida en términos de construcciones sociales impuestas a cuerpos sexuados.

\section{Bibliografía}

Aguirre, J. (2013): Platón y la poesía. Ion, Madrid, Plaza y Valdés.

Azaovagh de La Rosa, A. (2011): «Cuerpo e iconicidad: los rostros de la humanidad», in: Sierra González, Ángela y Yasmina Romero Morales (eds.): Actas del V Congreso Internacional de la Sociedad Académica de Filosofía «Razón, crisis y utopía», Santa Cruz de Tenerife, Universidad de La Laguna/Sociedad Académica de Filosofía, pp. 73-83.

Beristáin, H. (2001): Diccionario de retórica y poética, México, UNAM.

Bernabé, A. (1995): «Una etimología platónica: sôma-sêma», Philologus, nº 139.2, pp. 204-237.

Bernabé, A. (2011): Platón y el orfismo. Diálogos entre religión y filosofía, Madrid, Abada. Cassertano, G. (2010): «La giustizia come il fare le cose proprie (Plat. Resp.)», in: A. Arbea y R. Inostroza (eds.): La idea de justicia en la antigüedad clásica, Santiago de Chile, Universidad Metropolitana de Ciencias de la Educación, pp. 109-131.

Chantraine, P. (1968) : Dictionnaire étymologique de la langue grecque. Histoire des mots, Paris, Éditions Klincksieck.

Crespo, E., (2015): «La aparición del concepto de cuerpo en época posthomérica», in: C. Sánchez e I. Escobar (eds.): Dioses, héroes y atletas. La imagen del cuerpo en la Grecia antigua, Madrid, Comunidad de Madrid/República Helena, pp. 45-52.

Filgueiras de Araújo, H. (2011): «A estetização da alma pelo corpo no Fédon de Platão», Perspectiva filosófica (Recife), $\mathrm{n}^{\circ}$ 36, pp. 163-181.

García Gual, C. (1999): «El cuerpo humano y su descripción en los tratados hipocráticos», in: A. Pérez y G. Cruz (eds.): Unidad y pluralidad del cuerpo humano, Madrid, Ediciones Clásicas, pp. 63-79.

Hesíodo (1986): Teogonía, México, UNAM.

Hipócrates (1988): Tratados Hipocráticos. Vol. IV, Madrid, Gredos.

Homero (2013): Odisea, México, UNAM, 2013.

León-Portilla, M. (2006): La filosofía náhuatl estudiada en sus fuentes, México, UNAM.

Lombardi, T. (1994): «Alcune considerazioni sul mito di Pandora», Quaderni Urbinati di Cultura Classica (Roma), n 46.1, pp. 23-34. 
López, A. (1980): Cuerpo humano e ideología. Los conceptos de los antiguos nahuas, México, UNAM.

Martos Montiel, J. (1999): «La concepción homérica del cuerpo humano», in: A. Pérez y G. Cruz (eds.): Unidad y pluralidad del cuerpo humano, Madrid, Ediciones Clásicas, pp. 37-61.

Moreno Conde, M. (2015): «Entre la risa y el rechazo: la fealdad en la antigua Grecia», in: C. Sánchez e I. Escobar (eds.): Dioses, héroes y atletas. La imagen del cuerpo en la Grecia antigua, Madrid, Comunidad de Madrid/República Helena, pp. 187-200.

Píndaro (2002): Nemeas, México, UNAM.

Platón (2000): República, México, UNAM.

Platón (2004): Timeo, Santiago de Chile, Pontificia Universidad Católica de Chile.

Platón (2008): Gorgias, México, UNAM.

Platón (2011): Filebo, Madrid, Encuentro.

Platón (2013): Alcibíades, Santiago de Chile, Ediciones tácitas.

Rousselle, A. (1989): Porneia. Del dominio del cuerpo a la privación sensorial. Del siglo II al siglo IV de la era Cristiana, Barcelona, Península.

Santasilia, S. (2016): «Sugerencias para una posible fenomenología del límite», Interpretatio. Revista de Hermenéutica (México), nº 1, pp. 95-115.

Snell, B. (1965): Las fuentes del pensamiento europeo. Estudios sobre el descubrimiento de los valores espirituales de Occidente en la antigua Grecia, Madrid, Razón y fe.

Tapia, P. (2013): Vocabulario y formas verbales de la Odisea, México, UNAM. 